Supplement of Clim. Past Discuss., 11, 3241-3275, 2015

http://www.clim-past-discuss.net/11/3241/2015/

doi:10.5194/cpd-11-3241-2015-supplement

(C) Author(s) 2015. CC Attribution 3.0 License.

(c) (i)

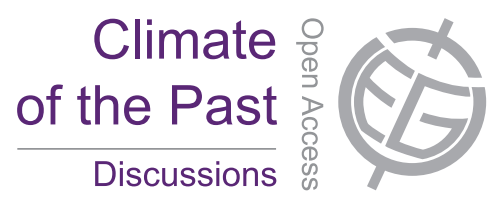

Supplement of

\title{
Paleoclimate reconstruction in the Levant region from the petrography and the geochemistry of a MIS 5 stalagmite from the Kanaan Cave, Lebanon
}

C. Nehme et al.

Correspondence to: C. Nehme (carole.nehme@ naturalsciences.be)

The copyright of individual parts of the supplement might differ from the CC-BY 3.0 licence. 


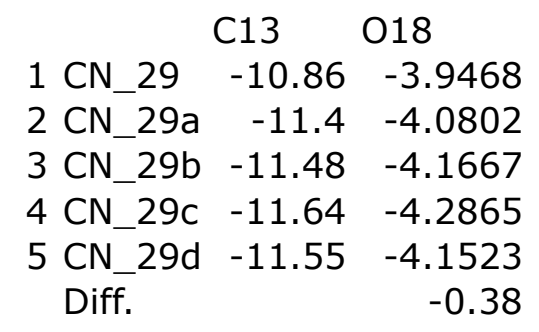

C13 018

1 CN_85 $-11.58 \quad-4.076$

2 CN_85a $-11.66-4.0035$

$3 \mathrm{CN} \_85 \mathrm{~b}-11.66-3.8564$

4 CN_85c $\quad-11.5-3.9893$ Diff.

0.22

C13 018

1 CN_129 $-11.58-4.4745$

2 CN_129 $-11.52-4.3271$

3 CN_129 $-11.49 \quad-4.277$

4 CN_129 $-11.5 \quad-4.2707$

5 CN_129 $-11.4 \quad-4.2576$

Diff.

0.22
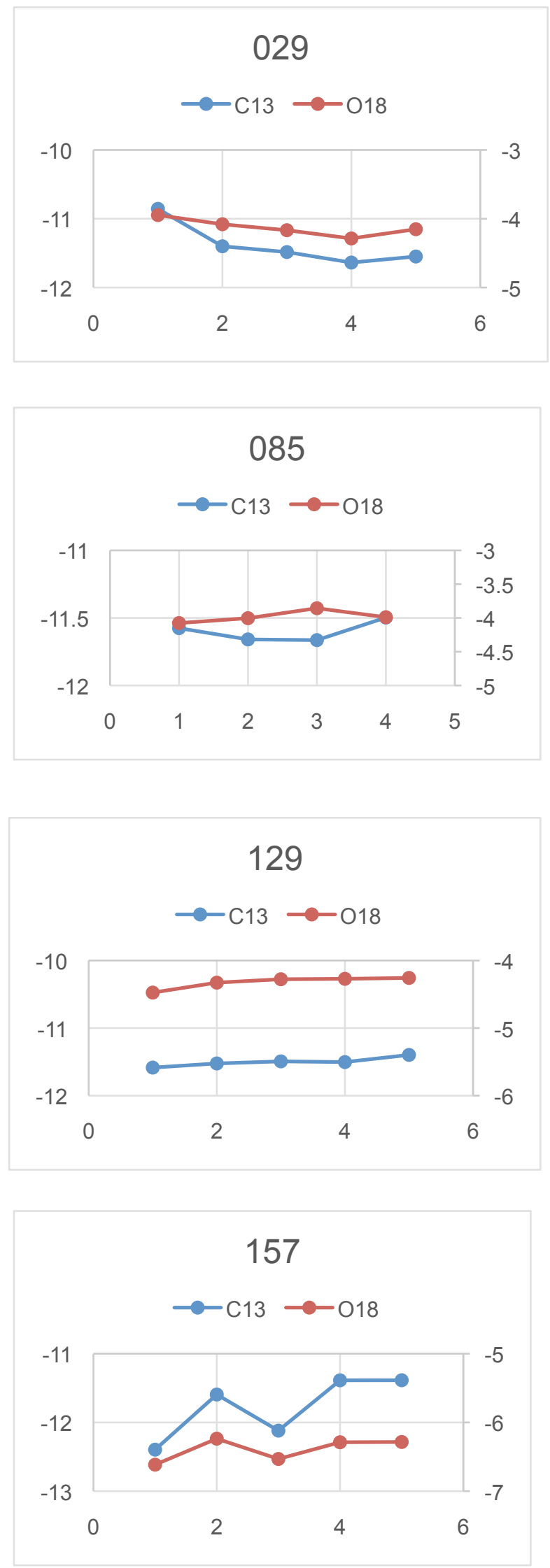


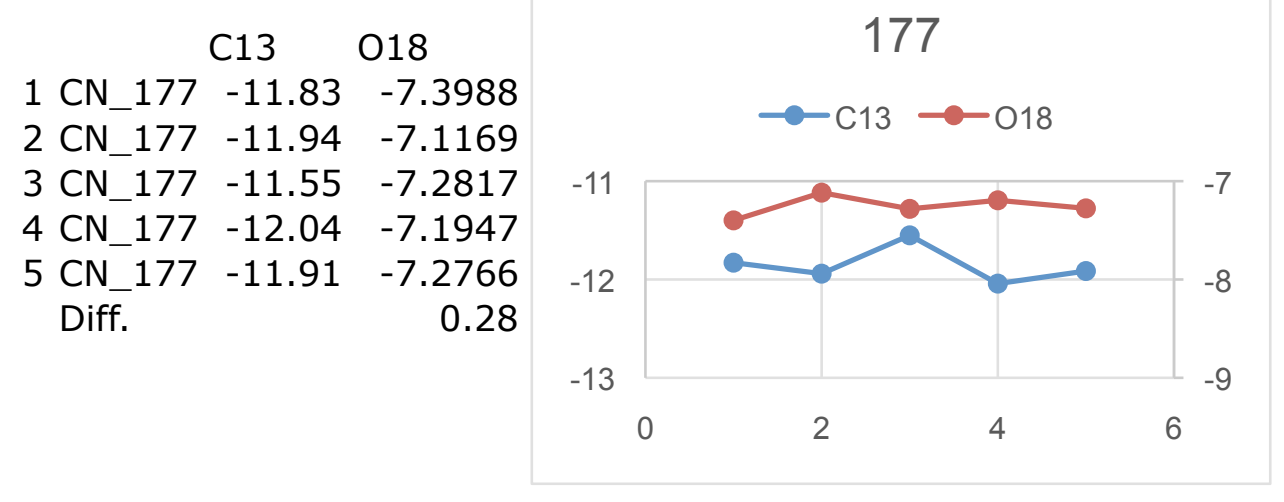

